\title{
Learning from Corporate Memory and Best Practices
}

\author{
Nada Matta and Oswaldo Castillo Navetty \\ Charles Delaunay Institute, Tech-CICO Team, University of Technology of Troyes, Troyes
}

France

\section{Introduction}

Knowledge management is currently defined as a process of identification, formalization, disseminating and use of knowledge in order to promote creativity and innovation in companies (Grundstein, 2000). This process (Fig. 1) takes into account the transformation and the evolution of tacit to explicit knowledge (Nonaka \& Takeushi, 1995) and of individual to collective knowledge.

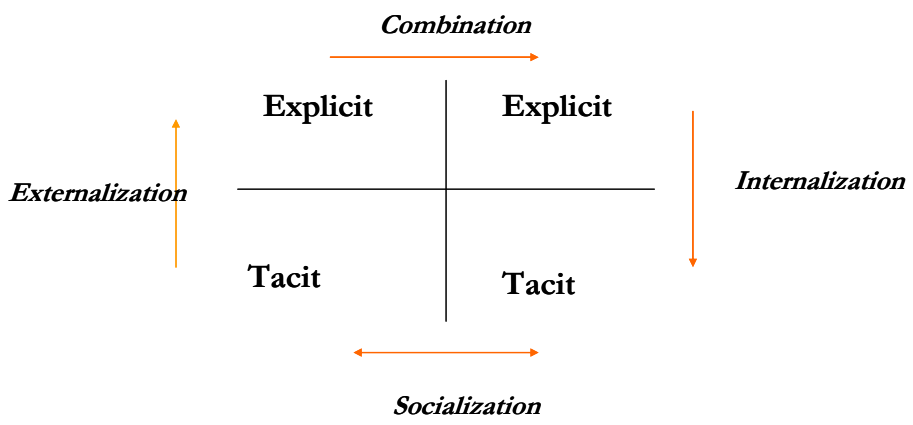

Fig. 1. Knowledge Management (Nonaka \& Takeushi, 1995).

Knowledge Engineering (Charlet, 2003), (Aussenac-Gilles et al, 1996) offers a rational framework allowing a representation of knowledge obtained through the experiments (Matta, Zaher, 2008). This technique found a great application in knowledge management and especially to capitalize knowledge (Dieng \& Matta, 2002). In fact, the rational representation of knowledge allows their exploitation and their re-use. It is a necessary condition to allow a re-use and a knowledge appropriation. Behaviour laws provide strong semantics to observe as well as an argumentation of this behaviour, ready to be reproduced to solve new problems (Newell, 1982). These techniques provide semantic representation of knowledge that can answer to main objective of knowledge management: knowledge externalization and internalization (Nonaka \& Takeushi, 1995). For that, some knowledge management approaches aim at making explicit the problem solving process in an organization. Their techniques are inherited mainly from knowledge engineering. So, we find in these approaches in one hand, models representing tasks, manipulated concepts and 
problem solving strategies, and in the other hand, methods to extract and model knowledge. We note for instance MASK (Ermine, 2002), (Dieng et al, 2001) and REX (Malvache \& Prieur, 1993) methods. These methods are used mainly to extract expertise knowledge and allow defining corporate memories.

A corporate memory is defined as the "explicit and persistent representation of the knowledge and the information in an organization » (Van Heijst et al, 1997). We can distinguish several types of memories: profession memory, project memory and organization memory. The sharing and the appropriation of the corporate memories are still real blocking points within organizations. The methods of knowledge management are not sufficient to allow an effective appropriation of the knowledge by the actors of the company. However, the objective of knowledge capitalization is indeed sharing and re-use of an experience with the aim of optimizing the process of organizational learning.

Sharing documents, information and experiment without structuring of these information and feed-back analysis as used currently on social network (Wenger, 1998) as support of knowledge sharing, is not sufficient to enhance learning. In fact, the "how" is shared but not the "what". Behaviour laws provide strong semantics to emphasize reason of this behaviour. To enhance learning in an organization, the representation of knowledge has to emphasize the know-what and know-how (Easterby-Smith \& Lyles, 2007). In fact, to enhance learning from organization, it is necessary to emphasize when and how activities and especially what and why these activities (Colin \& Spender, 1998).

An experiment is done to enhance learning from experience. In fact, we use CSAO (Castillo \& Matta, 2005), an approach that combine knowledge engineering and pedagogical techniques and we define a course that push engineering school students to learn knowledge capitalization methods. These students are not familiar to knowledge engineering techniques but they know software engineering approaches (modelling and development).

CSAO approach (Fig. 2) pushes from one side, (by using knowledge engineering techniques) to structure expertise in order to emphasize the process of the activity, the goals and steps done by expert for each activity and concepts manipulated in each step. From another side, it proposes (based on pedagogical principles) to define practical exercises, guided by a framework that help learners to auto-evaluate their progress. CSAO are developed at the beginning to help in knitting learning CSAO (Castillo \& Matta, 2005).

The result of our experience is very fruitful, students are able, after succeeded this course to model knowledge in companies. Reports results are more complete and detailed than when they are assisted by a teacher.

We present in this chapter the principle base of the CSAO, by summarizing knowledge engineering techniques and pedagogical bases. Then we present the experience: conditions, process, guides and results. A discussion concludes the chapter by analyzing the relation between these techniques and social network.

\section{Appropriation of a profession memory}

One of the main motivations for building a memory in a company is the improvement of employees' learning. This learning can be at an individual, group or organizational level (Dieng et al, 2001). By looking at our preliminary experiences of defining a profession memory (explicit representation of an activity in a specific domain (Castillo \& Matta, 2005), and more specifically at the learning from such memories, we noticed that the learning from 
a profession memory is not easy. These memories are generally presented under several points of view (classifications, constraints, processes, problem solving strategies, etc.). The links between these views are put in background because the knowledge formalization shows the nature of the knowledge. Learning and following the learning progress in such a memory can be easy for a knowledge engineer but it is complex for an organization's actor who is specialist on his profession and who wants to learn a know-how formalized by an expert in his domain.

To facilitate the learning from a profession memory, we adapted techniques from educational engineering by modifying the way of building the profession memory, and especially, by showing this memory, to organization's actors in different ways.

\section{Educational engineering}

According to Paquette (Paquette, 2002), educational engineering or training engineering has to offer principles, procedures and tasks that allow to:

- Define the contents of a training by means of a structural identification of the knowledge and the recounted,

- Realize an educational scenario of the training activities and to define the context of use and the structure of the learning material,

- Define infrastructures, resources and services necessary for distributing lessons and preserving their quality.

So, educational engineering leans on two processes in the heart of the knowledge management (Paquette, 2002), (Rolland, 2000):

- At first the extraction of the knowledge from domain experts or documents;

- Then the acquisition, by the organization actors, of the knowledge by learning;

- The transformation of the information in knowledge by means of the formal on informal activities taking a variety of forms and supports.

Complete training of an operator contains three phases: learning or intensification of the general knowledge; learning of procedures and typical solutions; and training on simulator in "real situations". This last phase is more recognized for operational learning (Rolland, 2000). During this phase, "the operational competence can be developed, and the expertise level is incremented. The student learns here of how to use knowledge learnt previously quickly, deliberately, in any situation and under any degrees of stress and workload". In her work, Kalina Yacef (Yacef, 2003), found the following conclusions, from structuring of the operational training point of view:

- This one has to be made by the practice, in situation of action;

- This practice must be structured so as to respect the development of levels of expertise following the tasks and to be directed to purposes;

- The competence evolve with the practice, it is necessary to take measures of evaluation based on the result of the actions and not on the reasoning follow-up;

- The acquisition of competence is made on one hand by the automation of certain behavior and on the other hand by the development of capacities to solve new problems.

These studies allow us to develop a learning system (Castillo \& Matta, 2005). Our particular interest is the construction of a system based on a profession memory. By taking into account the practical knowledge (problem solving) of the training contents, our system becomes a practical learning system. 


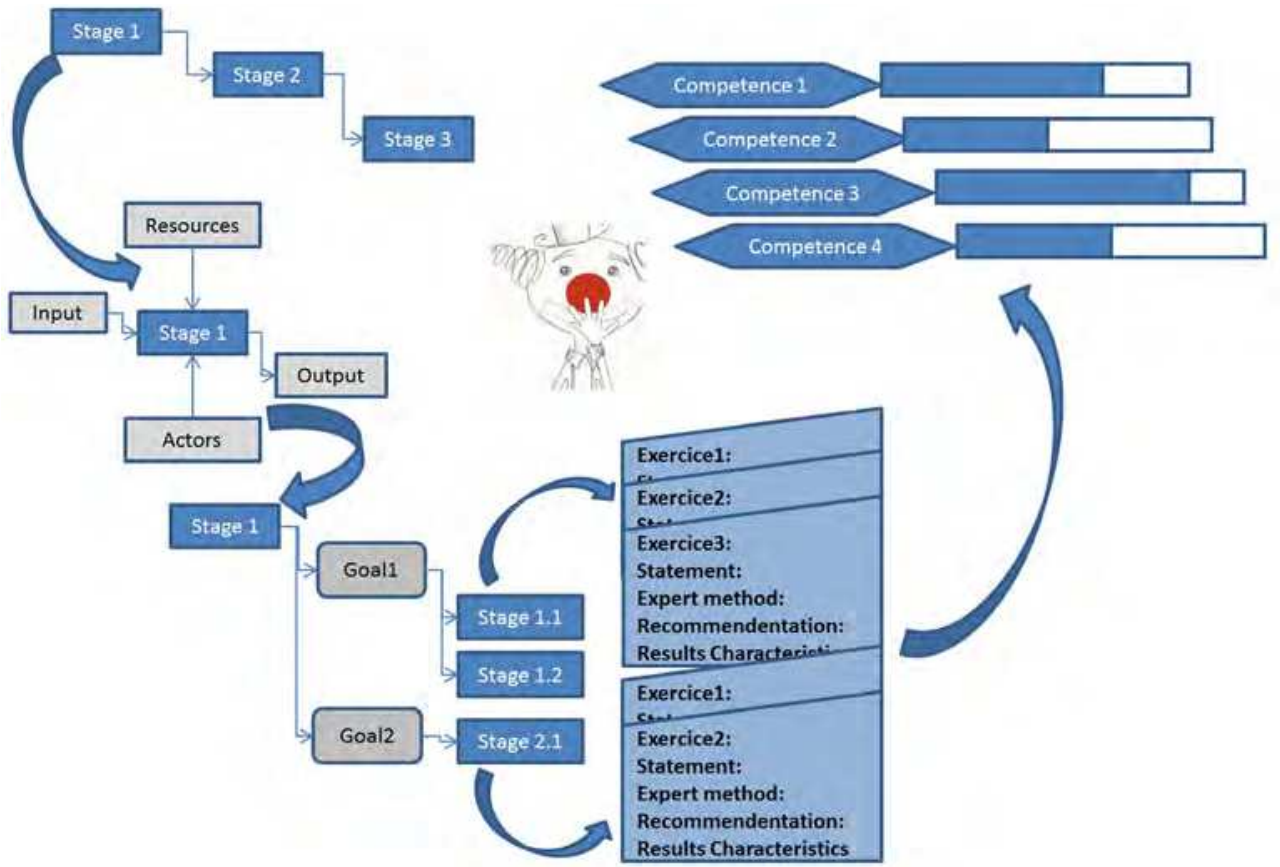

Fig. 2. Progression process illustration of knowledge learning from experience (Castillo \& Matta, 2005).

\section{CSAO: Proposition of a practical learning system}

We thus try to show the difficulties of a domain and how to encounter them. It is for that reason; in our work we feel the need to exploit concepts of knowledge engineering especially the process of knowledge formalization. Indeed, the knowledge engineering techniques allow to emphasis the difficulties of an activity while the educational engineering allows estimating the learning progress levels. We shall base our approaches on the one hand, on some educational engineering evaluation techniques as diagnosis, training approaches and problem solving learning and on the other hand on knowledge engineering techniques to extract and restructure the contents of the training and of the evaluations. The first postulate to be considered is the expert source of the knowledge has to participate as well in the defining of the profession memory as in the definition of some means for knowledge appropriation (Fig. 2). An activity process is used as a guide of progression of learning. For each stage, is associated Input/output, knowledge type needed to do the step and the role of actors who can do this stage. Then, goals (objectives) and steps are described that show how the expert performs each stage (Fig. 3).

Exercises are also associated to each stage and to all process. A sheet (Fig. 4) guides the learner to do exercises. In each sheet guide, stage objectives, expert problem solving, recommendations and result characteristics are defined by the expert. The learner tries to satisfy the stage objectives. The expert problem solving representation (and especially subobjectives) guides him in this purpose and show him the goal of techniques used to solve the problem. The recommendations and result characteristics allow learner to evaluate his result. 


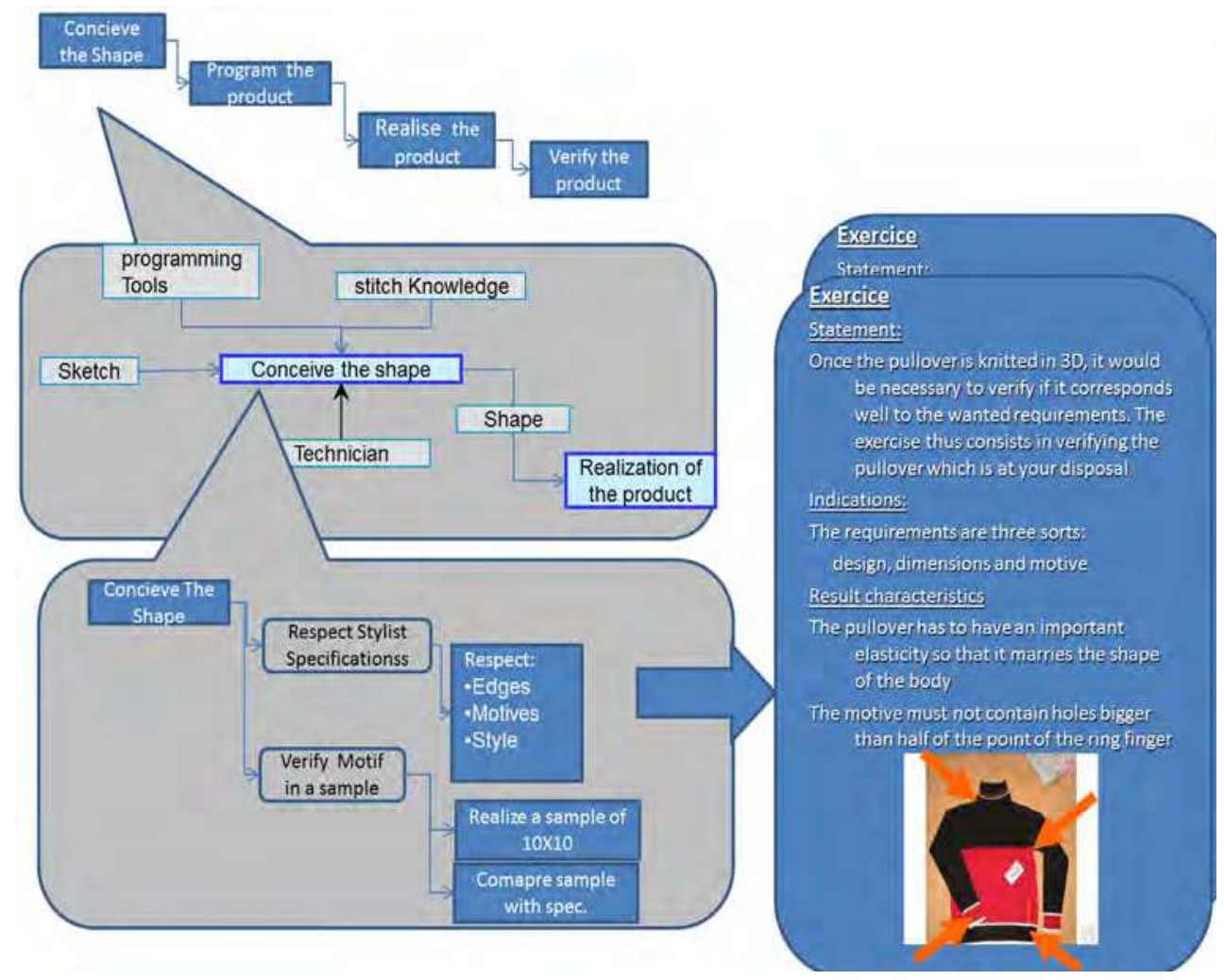

Fig. 3. Organization of the content of expertise (Castillo \& Matta, 2005).

\section{Experimentation: Application on a course}

We use CSAO and especially the guide sheet in order to tackle knowledge engineering learning. In fact, we organize in our university a course on Knowledge Engineering. This course is for software engineering students. They have information about engineering techniques: specification, design, etc, of software and information system. But they do not have any information about knowledge, expertise, knowledge modelling, etc. We also note the difference between Software Engineering method that guides to build a system from an idea, a need and Knowledge Engineering approach that start from an expertise and model it. Even two approaches are belonging to engineering techniques (modelling) but there is a basic difference on the objects and methods used. So, Knowledge Engineering course is new to student and they need practical learning in order to appropriate its techniques, especially that the entire course is only done on 6 months, students do not have time to experiment notions in several applications. 


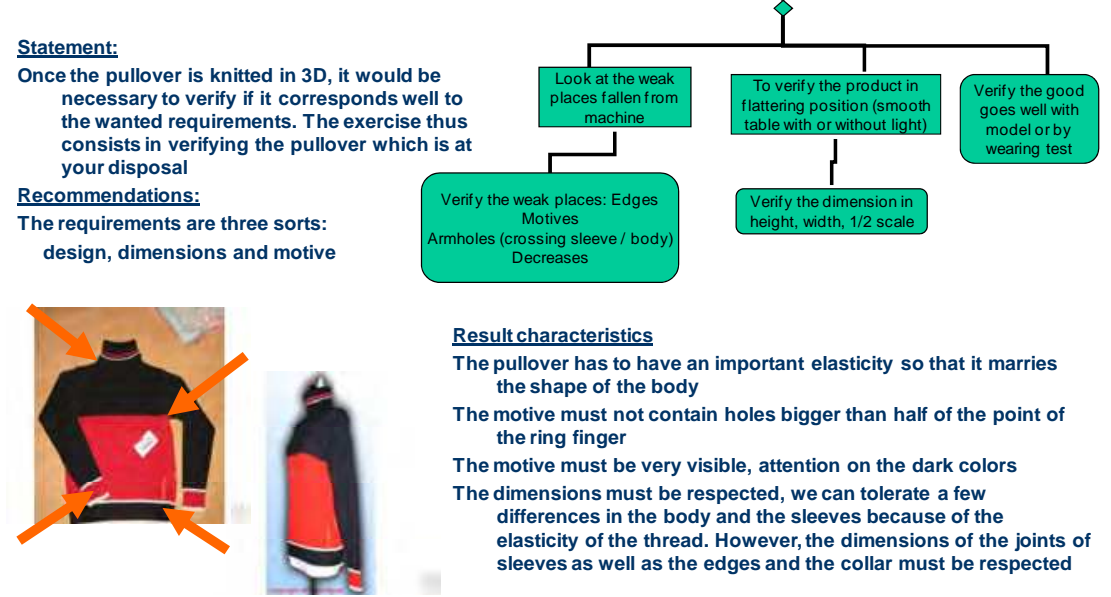

Fig. 4. Exercise sheet guide (Matta, Castillo, 2009).

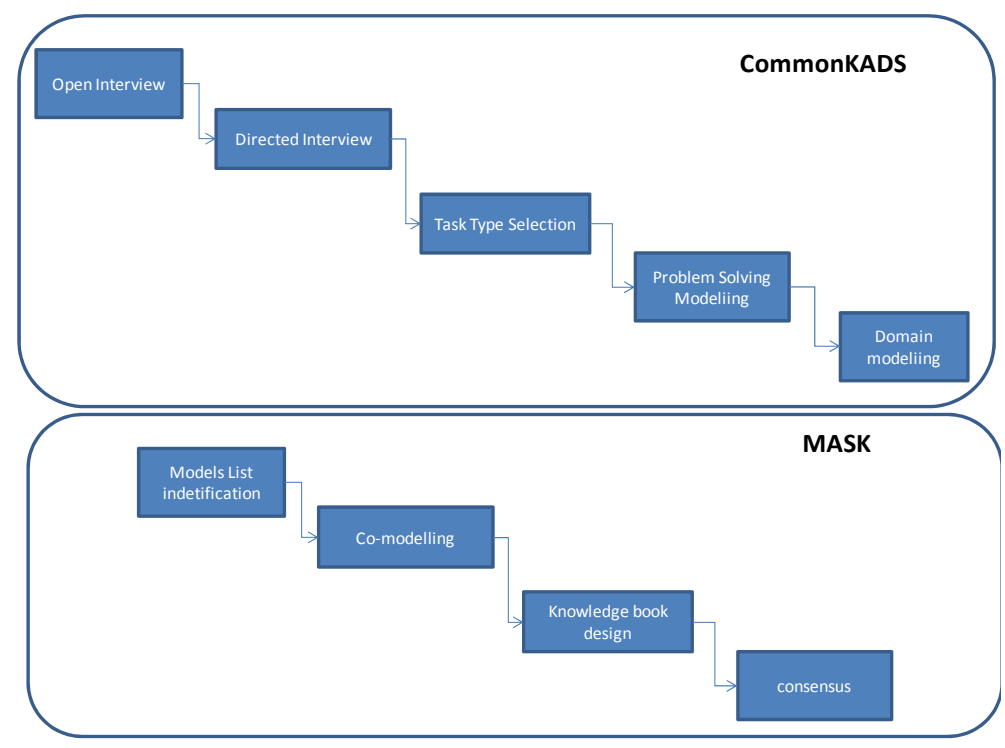

Fig. 5. Projects process: modelling with CommonKADS and with MASK methods.

The course is organized as projects. Students have an access to principles and theory on Knowledge Engineering as reports and recorded courses. These courses are organized as a normal course: Introduction to Knowledge Engineering, Modelling approaches (CommonKADS, etc.), Applications and Implementations (KBS, Knowledge Management, etc.). Students need to apply these techniques in order to learn how to model knowledge. So, two projects are organized for this aim. They have to apply two knowledge engineering 
approaches CommonKADS (Breuker \& Vand de Velde, 1994) and MASK (Ermine, 2002) in real applications. Sheet guides and process are modelled based on an expertise on knowledge engineering applications (12 years on building KBS and knowledge book) (Matta, Castillo, 2009).

\subsection{Projects organization}

Students are organized on teams. In each team, one student is considered as an expert if he has an expertise (during some years) in an activity (sports, games, etc.). Each team have to produce a report in which the related expertise is modelled using CommonKADS (for the first Project) and using MASK (for the second project). They have 2 months for each project. They follow at first the knowledge engineering process from interview to modelling (Fig. 5). For each phase, they are guided by a sheet guide (Fig. 6) and (Fig. 7). They have to evaluate their intermediate results based on results characteristics defined in sheet guides for each phase. They have also to validate models with the expert. Final results (reports) are then sending to the knowledge engineering expert for final evaluation.

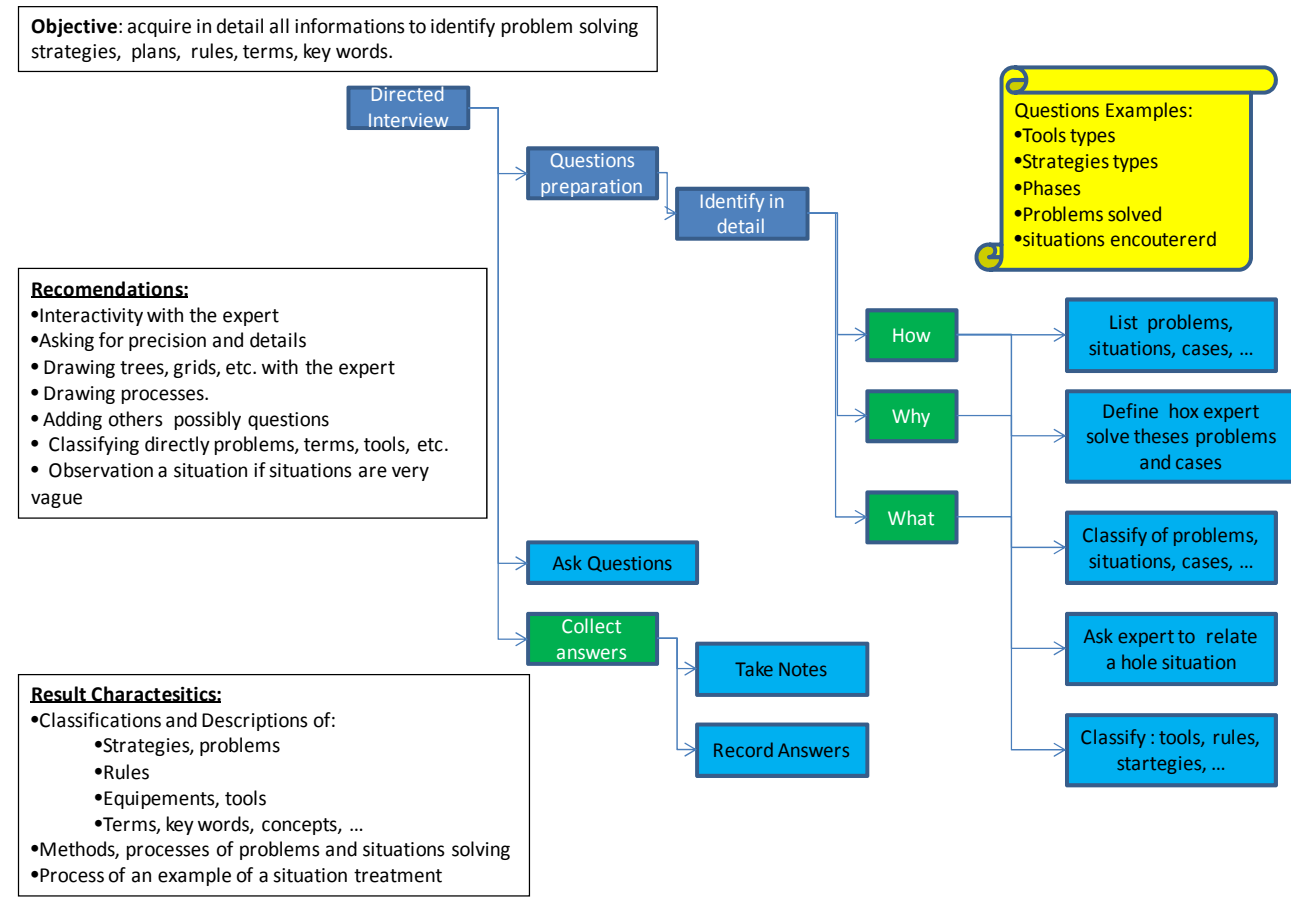

Fig. 6. Sheet Guide for the Phase Directed Interview using CommonKADS method.

\subsection{Results}

These experiences are done since two years. Each project type has 2 months as delay. Students have to give results as complete reports: models organized as deliverables (Fig. 8): problem solving model (Fig. 9), ontology (Fig. 10)for CommonKADS and a knowledge book with Index, models, comments ... for MASK (Fig. 11). 


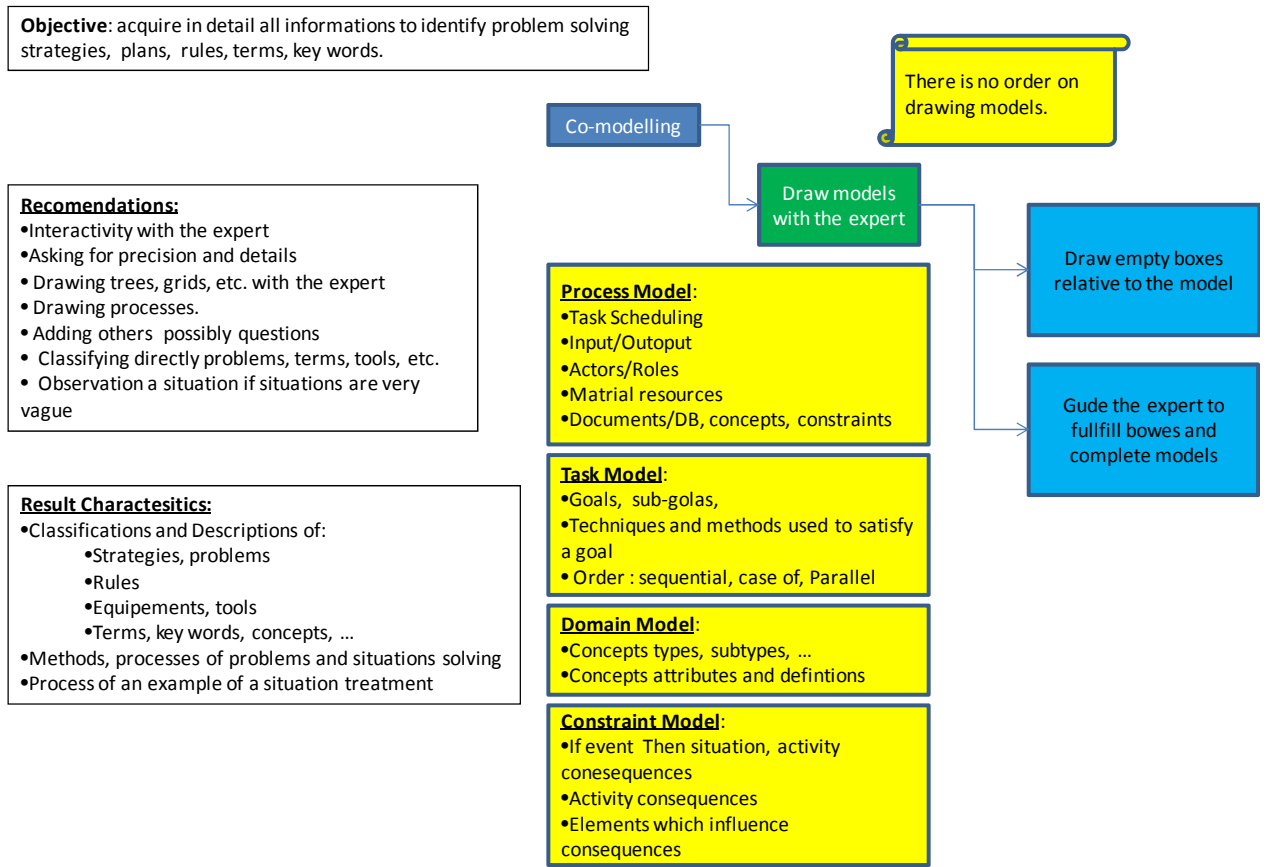

Fig. 7. Sheet Guide for the Phase Co-modelling using MASK method.

1. Introduction: Objectives

\section{Basket Ball Expertise}

2. Knowlekdge Acquisition :

1. Free Interview: Global process model

2. Directed : Interview :

1. CLassifications: Ground composition, players types, equipements, attacks strategies, defense strategies, problems, infractions, mistake types

2. Case models: attack, Screen « Pick \& Roll », offensif systme "SHORT », defense activity, playing situation analysis, example of basket game

3. Problem Solving Modelling:

1. Strategies: defensive, offensive, evaluation, mistake diagnostic, repair

2. Global Model of problem solving

4. Domain Model:

1. Types: players, equipements, infrastructures, attack, defense, infraction,s mistakes

2. Conceptual Graphs: mistakes/infractions, play actions, players equipements

3. Global Domain model

5. Conclusion

Fig. 8. An example of report Index: modelling of Basket Ball expertise with CommonKADS. 


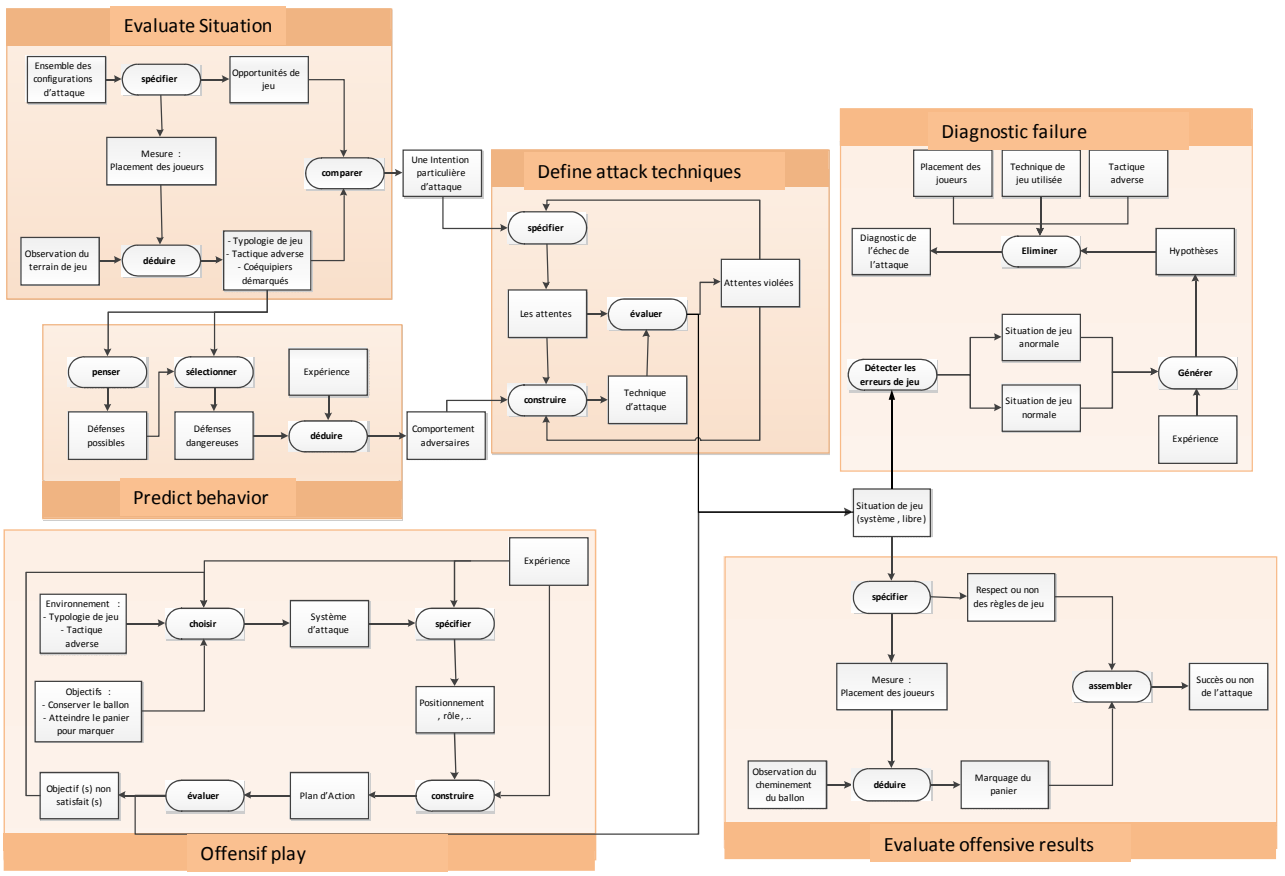

Fig. 9. Example of results (CommonKADS problem Solving model of "basket-ball" expertise).

$90 \%$ of projects are complete. Students took time to go in details and identify deeply expert's tasks and model them. Their analysis is very good. Models resulted show expert methods and heuristics. They can be used to support learning from studied expertises. In fact, when they are assisted, students model only one case of knowledge. They do not duplicate models. Teacher has to negotiate with them in order to repeat their task and model several examples. When they work by their own selves, they have to satisfy results characteristics specified in sheet guide. So for each type of model, they repeat their task and they model several examples in order to enhance heuristics rules. The "why" and the "what" is emphasized in models. They take time to go deeply and acquire several aspects and not settle for only few aspects of expertise. By repeating their task, learning is in progress. Students go deeper more and more in each modelling task and learn know-how and specially, success key of each task. They can control very well expertise modelling and its complexity. 

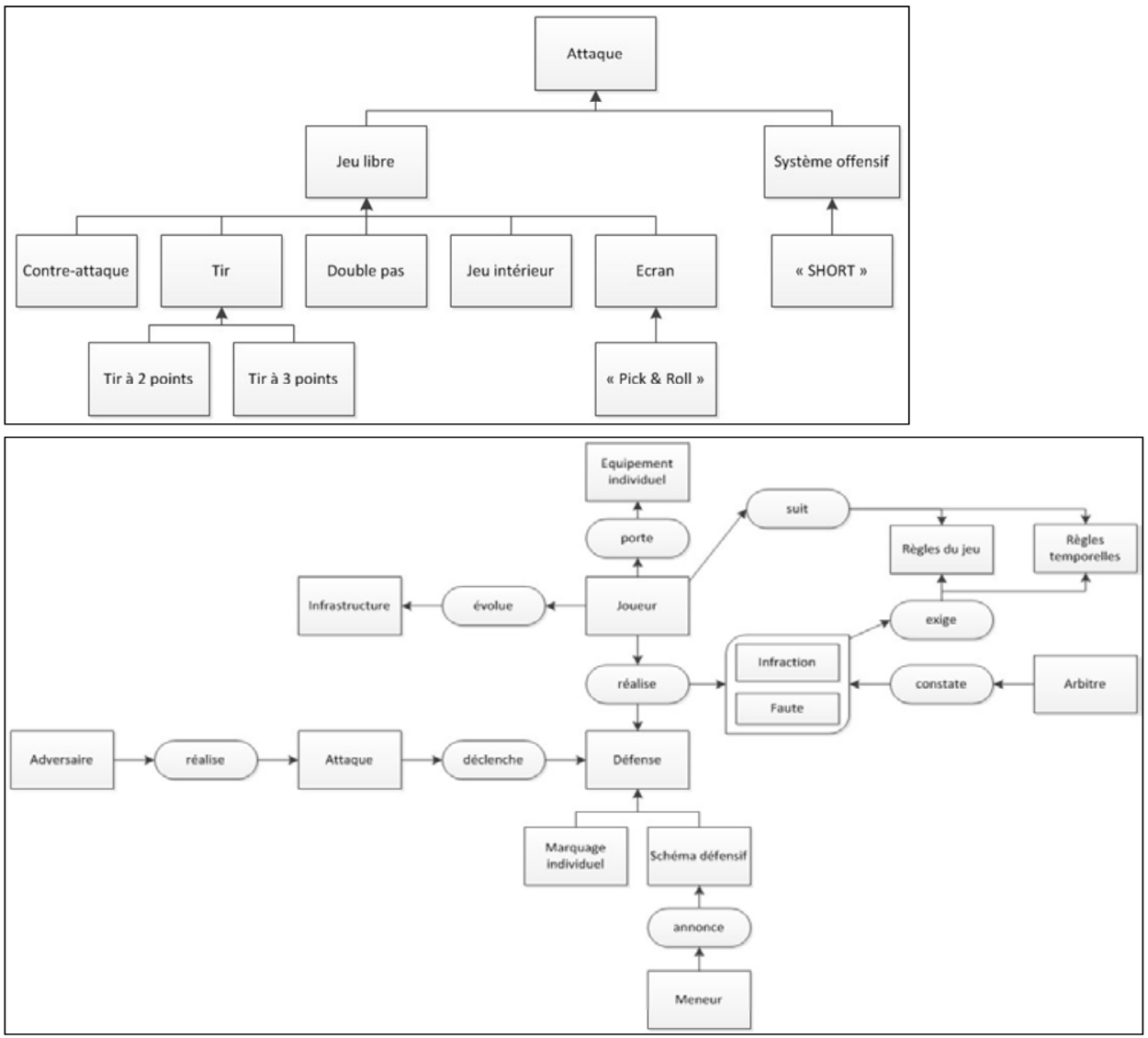

Fig. 10. Example of results (CommonKADS domain model of "basket-ball" expertise).

Each year, an evaluation of the course is done:

- Students appreciate recorded courses but it is not sufficient for them. When they discover these courses, they cannot be able to model expertise. That confirms our idea that only expertise models are not sufficient to enhance learning and internalization. Expert reasoning is at another level than learners. So showing models even with specific guidelines cannot help people to appropriate this knowledge.

- Guidelines sheets are much appreciated and more used than courses. They are guided by these sheets and especially by recommendations and results characteristics. In fact, these elements help them to evaluate their results at each step and to modify them. That is the main reason that the final result was very complete and models are deeply defined.

- Guiding modelling steps by steps make easily the appropriation of the expertise. At the beginning, they are afraid about the complexity of their task: modelling and expertise with its different aspects. But when they followed steps of modelling, they do not feel the complexity. That is a confirmation of the Newell (Newell, 82) theory: complex problem solving has to be decomposed in steps in order to understand it. 
- Pushing students to emphasize the "why", and the "what" of the expertises using the "how", is the main reason of the deeply modelling and the success of results.

This course was at the beginning organised as a normal course with a presentation of the theory and assisted projects. The results were not very complete. Students (except some of them) did not go in details and models deeply expertise. We analysed the problem and we identify two main reasons: 1- the difference on reasoning level between the knowledge engineering expert who assist students and students understanding, 2- students do not take time to go deeply and understand knowledge modelling principles. That pushes us to use $\mathrm{CSAO}$ in order to enhance learning of knowledge engineering.

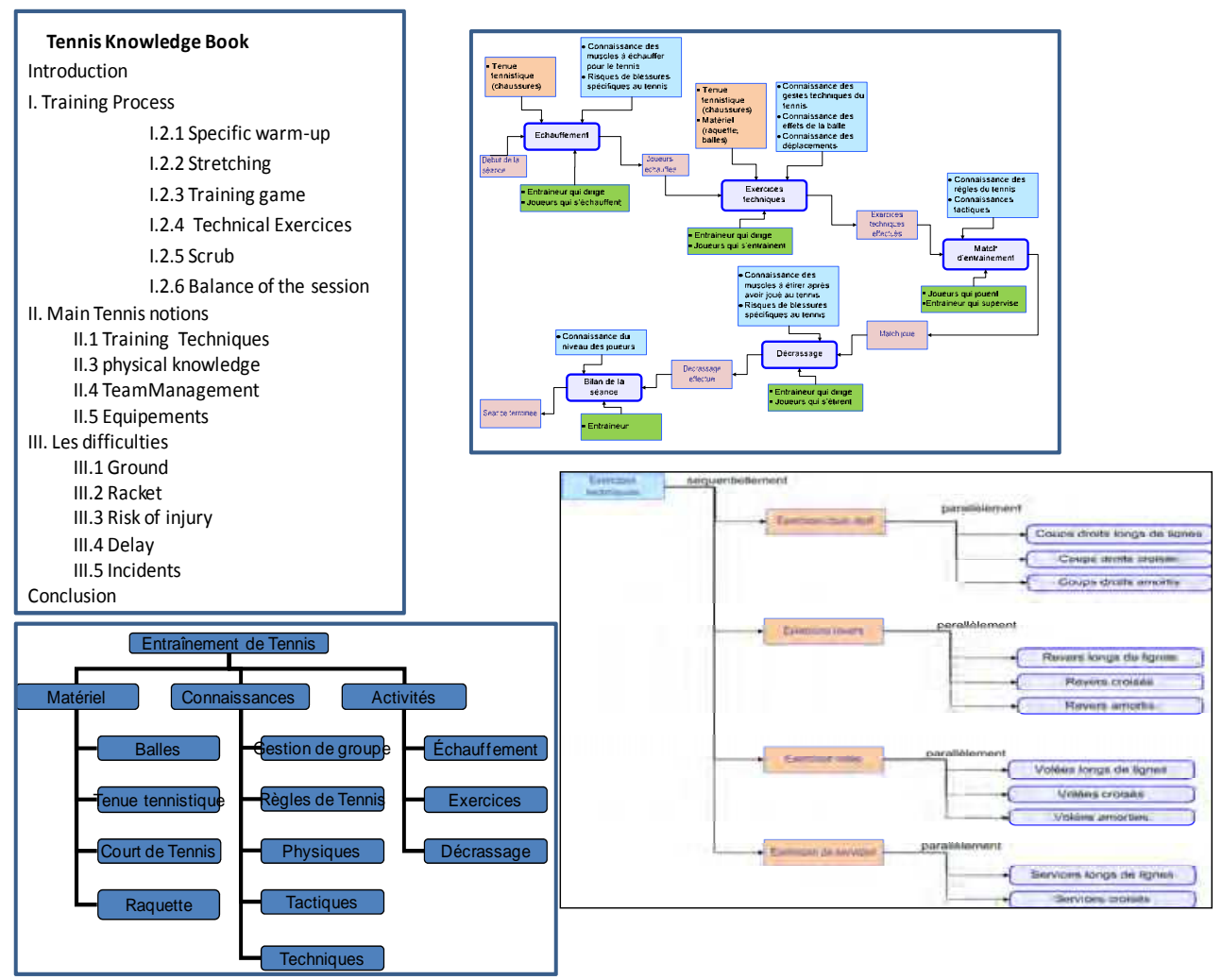

Fig. 11. An example of knowledge Book: Modelling of Tennis expertise with MASK.

\section{Conclusion}

Knowledge management is a process which enhances as well the knowledge capitalization as the sharing and the appropriation of this knowledge. Several techniques of knowledge capitalization were defined. However, the appropriation of the knowledge remains another subject to be deepened. The phase of appropriation requires a quite 
particular attention because of its success is going to depend on the efficiency of the organizational learning and thus the performance of the company partially. Otherwise, educational engineering techniques supply devices (teaching equipment, tools of evaluation and process of learning) to assist the appropriation of the knowledge. We studied these techniques to supply a device of appropriation of knowledge formalized in the form of profession memory.

We present in this chapter, an example of the use of the CSAO method to enhance learning of practice knowledge. CSAO is based on two techniques types: knowledge engineering (to structure practice knowledge) and educational engineering (to enhance learning). We show that the use of CSAO is more benefit that a traditional educational techniques, because students are pushed to evaluate their own work and to go deeply on their study and modelling. They have more autonomy and self control on their work that is why their results are more analytic.

We aim at applying CSAO on other type of course: "Enterprise Resources Planning" ... and on professional learning. That helps to complete the approach to tackle other type of evaluation and the progression on learning.

CSAO was defined at the beginning to enhance professional learning in an organization. We plan to apply it in several applications than textile and integrate it in organizational learning tools. For instance, social networks between actors and learners can be a good support to share problems to deal with. At the same time, actors need also several access types to a professional memory as a decision support and not only learning support. They are several techniques studied for this aim (semantic web, CBR, etc.). We study how to integrate these techniques with our learning support CSAO.

Otherwise, professional memory has to be updated and enriched with knowledge emphasizing from new activities. Tagging techniques (Cahier \& Zacklad, 2002) have to be integrated with structuring and knowledge representations in order to enhance memory updating.

Other type of knowledge can be produced in cooperative activity. We note specially negotiation, coordination, and organization knowledge. We study how to keep track and represent this type of knowledge in a specific domain: design projects (Matta et al, 2011).

\section{References}

Aussenac-Gilles, N.; Laublet, P.; Reynaud, C. (1996). Acquisition et Ingénierie des connaissances, Tendances Actuelles, Cepadues Editions, 1996.

Breuker, J.; Van de Velde, W. (1994). Common-KADS Library for expertise modelling Reusable problem solving components, Frontiers in Artificial Intelligence and Applications, J. Breuker and W. Van de Velde (EDS), Amsterdam: IOS.Press 1994.

Cahier, J.-P.;Zacklad,M. (2002). Towards a Knowledge-Based Marketplace model (KBM) for cooperation between agents, In Proc. of COOP'2002 conference, St Raphael, 4-7june 2002, IOS Press. 
Castillo, O.; Matta, N. (2005). A practical learning system for the French Textile and Apparel Institute. GESTS International Transactions on Computer Science, 1738-6438, December 2005, vol.24, $\mathrm{n}^{\circ} 1$, p. 8-20.

Colin, E.; Spender J.C. (1998). Managerial and organizational cognition: Theory Methods and Research, SAGE, 1998.

Charlet J. (2003). L'ingénierie des connaissances, Développements, résultats et perspectives pour la gestion des connaissances médicales, Mémoire d'Habilitation à Diriger des Recherches, université Pierre et Marie Curie, 2003.

Dieng-Kuntz, R. ; Corby, O. ; Gandon, F. ; Giboin, A. ; Golebiowska, J. ; Matta, N. ; Ribière M. (2001). Méthodes et outils pour la gestion des connaissances. 2eme edition. Dunod éditeur. 2001.

Dieng-Kuntz, R.; Matta, N. (2002). Knowledge Management and Organizational Memories, Kluwer Academic Publishers, 2002.

Easterby-Smith, M.; Lyles, M.A. (2007). Handbook of Organizational Learning and Knowledge Management, Blackwell, 2007.

Ermine J.L. (2002). La gestion de connaissances, J.-L. Ermine.- Hermès sciences publications, 2002.

Grundstein M. (2000), From capitalizing on Company Knowledge to Knowledge Management, chapter 12, pp. 261-287, in Knowledge Management, Classic and Contemporary Works, Morey D., Maybury M., Thuraisingham B. (Eds), The MIT Press, Cambridge, Massachusetts, 2000.

Malvache, P.; Prieur, P. (1993). Mastering Corporate Experience with the REX Method, Proceedings of ISMICK'93, International Synopsium on Management of industrial and corporate knowledge, Compiegne, October, 1993

Matta N.; Zaher L. (2008). Applications of knowledge Engineering for Design, Methods and Tools for effective Knowledge Life-Cycle Management, Bernard A., Tichkiewitch S. (Eds), Springer, 2008.

Matta, N.; Castillo, O. (2009). Learning from Profession Knowledge: Application on Knitting, IEEE proceedings of the $5^{\text {th }}$ International Conference on Signal-Image Technology and Internet based Systems, Marakesh, November, 2009.

Matta N.; Ducellier G.; Charlot Y.; Beldjoudi R.; Tribouillas F.; Hibon E. (2011). Traceability of Design Project Knowledge using PLM, In IEEE proceedinds of International Conference on Cooperation Technologies and sciences, Philadelphia, May, 2011.

Nonaka, I.; Takeuchi, H. (1995). The knowledge-Creating Company: How Japanese Companies Create the Dynamics of Innovation. Oxford University Press, 1995

Newell A. (1982). The Knowledge level, Artificial Intelligence Journal, 19 (2), 1982.

Paquette, G. (2002). "L'ingénierie pédagogique: pour construire l'apprentissage en réseau”, Presses de l'université de Québec, 2002.

Rolland, M. (2000). "Bâtir des formations professionnelles pour adultes", Editions d'Organisations, 2000

Van Heijst, G.; Schreiber, A.; Wielinga, B. (1997). Using Explicit Ontologies in KBS Development. International Journal of Human Computer Studies, Vol. 46, 1997.

Wenger, E. (1998). Communities of Practice - Learning as a Social System. Systems Thinker, June 1998. 
Yacef, K. (2003). "Some thoughts about the synergetic effects of integrating ITS and LMS technologies together to the service of Education". R. Calvo and M. Grandbastien (eds), Proceedings of Towards Intelligent Learning Management Systems, held in conjunction with AIED'03, University of Sydney, Australia, Sydney, 2003. 


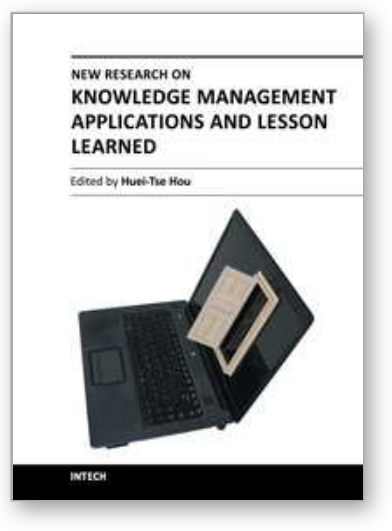

\author{
New Research on Knowledge Management Applications and \\ Lesson Learned \\ Edited by Dr. Huei Tse Hou
}

ISBN 978-953-51-0073-7

Hard cover, 242 pages

Publisher InTech

Published online 02, March, 2012

Published in print edition March, 2012

Due to the development of mobile and Web 2.0 technology, knowledge transfer, storage and retrieval have become much more rapid. In recent years, there have been more and more new and interesting findings in the research field of knowledge management. This book aims to introduce readers to the recent research topics, it is titled "New Research on Knowledge Management Applications and Lesson Learned" and includes 14 chapters. This book focuses on introducing the applications of $\mathrm{KM}$ technologies and methods to various fields. It shares the practical experiences and limitations of those applications. It is expected that this book provides relevant information about new research trends in comprehensive and novel knowledge management studies, and that it serves as an important resource for researchers, teachers and students, and for the development of practices in the knowledge management field.

\title{
How to reference
}

In order to correctly reference this scholarly work, feel free to copy and paste the following:

Nada Matta and Oswaldo Castillo Navetty (2012). Learning from Corporate Memory and Best Practices, New Research on Knowledge Management Applications and Lesson Learned, Dr. Huei Tse Hou (Ed.), ISBN: 978953-51-0073-7, InTech, Available from: http://www.intechopen.com/books/new-research-on-knowledgemanagement-applications-and-lesson-learned/learning-from-experience

\section{INTECH}

open science | open minds

\author{
InTech Europe \\ University Campus STeP Ri \\ Slavka Krautzeka 83/A \\ 51000 Rijeka, Croatia \\ Phone: +385 (51) 770447 \\ Fax: +385 (51) 686166 \\ www.intechopen.com
}

\author{
InTech China \\ Unit 405, Office Block, Hotel Equatorial Shanghai \\ No.65, Yan An Road (West), Shanghai, 200040, China \\ 中国上海市延安西路65号上海国际贵都大饭店办公楼 405 单元 \\ Phone: +86-21-62489820 \\ Fax: +86-21-62489821
}


(C) 2012 The Author(s). Licensee IntechOpen. This is an open access article distributed under the terms of the Creative Commons Attribution 3.0 License, which permits unrestricted use, distribution, and reproduction in any medium, provided the original work is properly cited. 